\title{
Prognostic Factors in Resectable Pathological N2 Disease of Non-small Cell Lung Cancer
}

\author{
Chen-Ping Hsieh ${ }^{1}$, Jui-Ying Fu², Yun-Hen Liu ${ }^{1}$, Cheng-Ta Yang ${ }^{2}$, Ming-Ju Hsieh ${ }^{1}$, Ying-Huang Tsai ${ }^{3}$, \\ Yi-Cheng $\mathrm{Wu}^{1}$, Ching-Yang $\mathrm{Wu}^{1}$
}

Background: N2-positive non-small cell lung cancer (NSCLC) exhibits extremely low survival rates. The role of surgery in operable locally advanced N2 NSCLC remains controversial. In this study, we tried to analyze the role of surgery in resectable N2 NSCLC and the relationship between survival and clinico-pathologic factors from a pathologic point of view.

Methods: 108 resectable pathologic N2-positive NSCLC patients, diagnosed from January 2005 to July 2012, were enrolled in this study. We retrospectively reviewed the medical records, image studies, and pathology reports to collect the clinico-pathologic factors in these patients.

Results: $\quad$ Those who received lobectomy $(p=0.002)$ and had a metastatic lymph node ratio less than $0.4(p=0.01)$ had a better overall survival rate. In addition, our study also showed that

\section{At a Glance Commentary}

Scientific background of the subject

Poor survival rate was identified in pathologic N2 lymph node positive nonsmall cell lung cancer patients. We tried to identify the factors that may affect the prognosis.

\section{What this study adds to the field}

Patients with poor prognostic factors may need more individualized follow-up programs in order to evaluate the disease and enhance survival. perineural invasion may play a significant role in disease-free survival $(p=0.01)$

Conclusions: Metastatic lymph node ratio greater than 0.4 and non-anatomic resection were poor prognostic factors for disease-free survival. Anatomic resection for selected N2 patients may play a crucial role in the overall survival rate. Perineural invasion showed an adverse impact on disease-free survival, but further investigation is warranted.

(Biomed J 2015;38:329-335)

\section{Key words: N2-positive lung cancer, non-small cell lung cancer, prognostic factor}

$\mathrm{N}$ on-small cell lung cancer (NSCLC) is a leading cause of death worldwide, as N2-positive NSCLC exhibits extremely low survival rates. ${ }^{[1]}$ There are many subgroups in this population and show similar survival curves. ${ }^{[2]}$ Literature review shows that most clinicians agree that NSCLC patients with N2 lymph node involvement are a heterogeneous group. ${ }^{[3,4]}$ There had been many reports that tried to subclassify this population. ${ }^{[1,5,6]}$ These studies showed that the disease prognosis was severe especially in the following clinical scenarios: Tumor cells involved multiple stations, subcarinal lymph node involvement, and presence of extracapsular extension. However, if patients with skip lesion can be identified, they would have better survival rates ${ }^{[1,5,6]}$ However, currently there is no conclusive consensus among the researches regarding these findings. In addition, the role of surgery for operable locally advanced N2 NSCLC remains controversial. ${ }^{[7-9]}$ The third edition of the American College of Chest Physicians evidence-based

From the ${ }^{1}$ Division of Thoracic and Cardiovascular Surgery, Department of Surgery, Chang Gung Memorial Hospital at Linkou, Chang Gung University College of Medicine, Taoyuan, Taiwan; ${ }^{2}$ Division of Thoracic Medicine, Department of Internal Medicine, Chang Gung Memorial Hospital at Linkou, Chang Gung University College of Medicine, Taoyuan, Taiwan; ${ }^{3}$ Division of Thoracic Medicine, Chang Gung Memorial Hospital at Chiayi, Chang Gung University College of Medicine, Taoyuan, Taiwan Received: Jun. 25, 2014; Accepted: Oct. 28, 2014

Correspondence to: Dr. Ching-Yang Wu, Division of Thoracic and Cardiovascular Surgery, Chang Gung Memorial Hospital at Linkou. 5 Fusing St., Gueishan, Taoyuan 333, Taiwan (R.O.C.). Tel: 886-3-3281200 ext. 2118; Fax: 886-3-3285818;

E-mail: wu.chingyang@gmail.com

DOI: $10.4103 / 2319-4170.145765$ 
clinical practice guidelines recommends that treatment plan for patients with discrete N2 involvement by NSCLC identified preoperatively (IIIA) should be made with the input from a multidisciplinary team. ${ }^{[9]}$ Ratto et al. reported good long-term survival and excellent local disease control. Surgery still plays an important role in the multimodality treatment of these patients. ${ }^{[8]}$ The International Adjuvant Lung Cancer Trial Collaborative Group has reported the results of a large randomized trial showing a significant improvement of survival with cisplatin-based adjuvant chemotherapy in completely resected NSCLC. ${ }^{[10]}$ In this study, we tried to analyze the role of surgery in resectable N2 NSCLC and the relationship between survival and the clinico-pathologic factors from a pathologic point of view.

\section{METHODS}

\section{Patients}

From January 2005 to July 2012, 108 resectable pathologic N2-positive NSCLC patients were enrolled in this study. The preoperative workup for the patients was reviewed thoroughly, which included chest computed tomography (CT), proton emission tomography (PET) or PET-CT, brain CT, and spirometery. Chest CT can be used to examine the anatomical relationship between lesions and vital organs, as well as to determine the possibility of curative resection. PET or PET-CT can be used to identify possible N3 and distant metastatic lesions. Brain CT can be used to rule out possible brain metastases. In addition, spirometery was utilized to evaluate patient's pulmonary reserve. All patients enrolled in this study were those with pathologic N2 disease without distant metastases. We retrospectively reviewed medical records in order to collect the clinico-pathologic factors of these patients. We did not obtain written or verbal informed consent from the patients. The data obtained from medical records was anonymized and de-identified prior to analysis. The study was approved by the Institutional Review Board (IRB) of Chang Gung Memorial Hospital and the IRB number is 99-1586B.

\section{Treatment strategy}

During the study period, chest physicians and surgeons discussed the treatment plan for the patients with $\mathrm{N} 2$ disease in a combined conference. The treatment strategy is shown in Figure 1. If image survey demonstrated that curative resection (i.e. lobectomy) was possible, with adequate pulmonary reserve (forced expiratory volume in $1 \mathrm{~s}>1.7 \mathrm{l}$ ), anatomic resection and mediastinal lymph node dissection were recommended. If image survey showed locally advanced disease, preoperative neoadjuvant therapy was be performed first, followed by repeat staging. If image survey revealed resectable, anatomic resection would be done for patients if they had adequate pulmonary reserve. For patients with poor pulmonary reserve, non-anatomic resection (i.e. wedge resection) and mediastinal lymph node sampling were done at the patient's request. All the patients received postoperative adjuvant therapy such as chemotherapy with or without radiation therapy.

\section{Follow-up}

All patients underwent regular follow-ups in the outpatient department. Disease relapse was confirmed with positive image findings or confirmed biopsy. Chest CT was used as the diagnostic tool for imaging. If disease relapse was suspected, further PET-CT or bone scan was arranged. If the lesion was easily accessible, biopsy was used in confirming the suspect lesion. Disease-free survival was defined as the period between the date of diagnosis and the date of relapse, confirmed by techniques such as positive image finding or biopsy. Overall survival was defined as the period from the date of diagnosis to the date on which the patient died. Local relapse was defined as disease relapse at surgical stump or ipsilateral thorax. Metastatic lesions which were located out of ipsilateral thorax were considered distant metastases.

\section{Statistical analysis}

All the collected clinico-pathologic factors were first analyzed with univariate analysis. Categorical variables were compared using Chi-square or Fisher's exact tests. Survival data were analyzed using the Kaplan-Meier method. The Cox regression model (semi-parametric model) was utilized for further identification of clinico-pathologic factors, in order to clarify the effect on disease-free and overall survival.

A $p<0.05$ was considered statistically significant. The reported confidence intervals $(\mathrm{CI})$ are assumed to have a coverage probability of $95 \%$. All the analyses were performed using SAS, version 9 (SAS Institute, Cary, NC, USA).

\section{RESULTS}

All the patient characteristics are shown in Table 1 . Mean age was 60.2 years and majority of them were males (56 patients, 51.9\%). Majority (94 patients, $87 \%$ ) of the patents did not receive preoperative neoadjuvant therapy. Surgical intervention was performed by the way of open thoracotomy during 2005-2009. The operation procedure was later shifted from open to video-assisted thoracoscopic surgery (VATS) beginning from 2010. Most patients (90 patients, $83.3 \%$ ) received anatomic resection (i.e. lobectomy). The most common cell type was adenocarcinoma (83 patients, $76.9 \%$ ), and the differentiation status of tumor cell was moderately differentiated (56 patients, $54.6 \%$ ). The $\mathrm{T}$-stage varied from T0 to T3 among the patients. One patient received preoperative neoadjuvant therapy prior to 


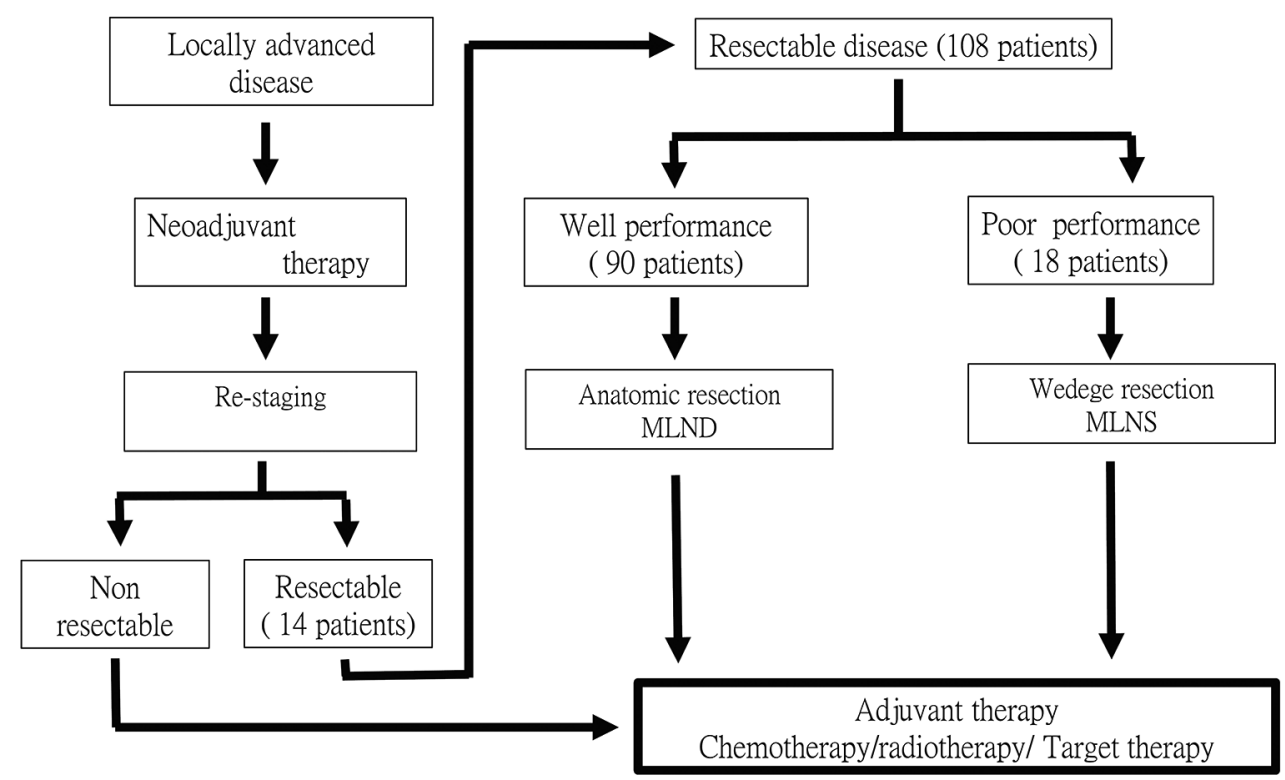

Figure 1: Treatment strategy.

operation, and the final pathologic examination showed no residual tumor within the resected specimen and classified it as T0. Six patients were classified as having T3 lesions. Three of them had tumor sizes larger than $7 \mathrm{~cm}$ in diameter. The other patients were diagnosed with partial chest wall invasion and received partial chest wall resection. The total number of lymph nodes and metastatic lymph nodes removed from the patients were $18.8 \pm 11.9$ and $4.1 \pm 3.5$, respectively. The median follow-up period was 869.5 days.

In this study, the 5-year disease-free and overall survival rates were 16.7 and $40 \%$, respectively [Figure 2]. The 19 clinico-pathologic factors that had been collected from medical records were further analyzed for their relationship with disease-free and overall survival rates. We found that the patients who received lobectomy $(p=0.004)$, those without perineural invasion $(p=0.005)$, and those with metastatic lymph node ratio lesser than $0.4(p=0.01)$ had better disease-free survival rates in univariate analysis. However, in the multivariate analysis [Table 2], only perineural invasion showed a significance in its adverse effect on disease-free survival rate (hazard ratio: 3.04, 95\% confidence limits $1.27-7.28 ; \mathrm{p}=0.01$ ) [Figure 3A]. We found that the patients who received lobectomy $(p<0.001)$, those without perineural invasion $(p=0.009)$, patients without mediastinal lymph node extracapsular extension $(p=0.01)$, and those with metastatic lymph node ratio lesser than $0.4(p=0.01)$ had better overall survival rates. By further multivariate analysis [Table 3], we identified that patients without perineural invasion (hazard ratio: $3.05,95 \%$ confidence limits $1.25-7.46 ; p=0.01$ ) [Figure 3B], those who received lobectomy (hazard ratio: $0.24,95 \%$ confidence limits $0.09-0.61 ; p=0.002$ ) [Figure 3C], and those with metastatic lymph node ratio less than 0.4 (hazard ratio: 2.18,
95\% confidence limits $1.13-4.18 ; p=0.01$ ) [Figure $3 \mathrm{~d}$ ] had better overall survival.

\section{DISCUSSION}

The role of surgery in the treatment of operable locally advanced N2 NSCLC remains controversial. ${ }^{[7-9]}$ The third edition of the American College of Chest Physicians evidence-based clinical practice guidelines recommend that treatment plan for patients with discrete N2 involvement by NSCLC identified preoperatively (IIIA) should be made with the input from a multidisciplinary team. ${ }^{\left[{ }^{[9]}\right.}$ Ratto et al. showed good long-term survival and excellent local disease control in their study. Surgery still plays an important role in the multimodality treatment of these patients. ${ }^{[8]}$ In addition, the International Adjuvant Lung Cancer Trial Collaborative Group has recently reported the results of a large randomized trial showing a significant improvement of survival with cisplatin-based adjuvant chemotherapy in completely resected NSCLC. ${ }^{[10]}$ Previous studies had reported that the 5-year survival rate of N2-positive NSCLC was around 19.2-30\%. ${ }^{[3,6,11-16]}$ In one large recent study, Koshy et al. showed that patients with clinical stage IIIA N2 NSCLC, who underwent neoadjuvant chemoradiation followed by lobectomy, were associated with an improved 5-year overall survival up to $33.5 \% .^{[17]}$ In our study, the 5-year disease-free and overall survival rates were 16.7 and $40 \%$, respectively. This result showed that our treatment outcome was non-inferior to previous studies. In patients who received anatomic resection and mediastinal lymph node dissection, the 5-year disease-free and overall survival rates were 20 and $48.2 \%$, respectively. All patients who received non-anatomic resection and mediastinal lymph node sampling died within 5 years after surgery. Therefore, anatomic 
Table 1: Patient characteristics

\begin{tabular}{|c|c|}
\hline Variables & $N(\%)$ \\
\hline Age $($ mean \pm SD $)$ & $60.2 \pm 11.5$ \\
\hline Gender-male & $56(51.9)$ \\
\hline Neoadjuvant Tx & $14(12.9)$ \\
\hline \multicolumn{2}{|l|}{ Neoadjuvant modality } \\
\hline None & $94(87.0)$ \\
\hline $\mathrm{CT}$ & $4(3.7)$ \\
\hline $\mathrm{CT}+\mathrm{RT}$ & $8(7.4)$ \\
\hline Target & $2(1.9)$ \\
\hline \multicolumn{2}{|l|}{ VATS/open category } \\
\hline Open & $60(55.6)$ \\
\hline VATS & $48(44.4)$ \\
\hline \multicolumn{2}{|l|}{ Category of operation } \\
\hline Non anatomic resection & $18(16.7)$ \\
\hline Anatomic resection & $90(83.3)$ \\
\hline \multicolumn{2}{|l|}{ Differentiated grade } \\
\hline G1 & $21(20.6)$ \\
\hline $\mathrm{G} 2$ & $56(54.9)$ \\
\hline G3 & $20(19.6)$ \\
\hline G4 & $5(4.9)$ \\
\hline N/A & $6(4.9)$ \\
\hline \multicolumn{2}{|l|}{ Cell type } \\
\hline Adenocarcinoma & $83(76.9)$ \\
\hline Non adenocarcinoma & $25(23.1)$ \\
\hline Visceral pleural invasion & $68(68.0)$ \\
\hline Angiolymphatic invasion & $61(61.6)$ \\
\hline Perineural invasion & $7(7.1)$ \\
\hline No. of LN (metastasis) & $4.1 \pm 3.5$ \\
\hline No. of LN (non-metastasis) & $14.8 \pm 10.6$ \\
\hline No. of LN (total) & $18.8 \pm 11.9$ \\
\hline \multicolumn{2}{|l|}{ N2 station (metastasis) } \\
\hline Single & $64(59.2)$ \\
\hline Multiple & $26(24.1)$ \\
\hline Others & $18(16.7)$ \\
\hline \multicolumn{2}{|l|}{ Type of skip lesion } \\
\hline Skip lesion & $50(46.3)$ \\
\hline Non skip lesion & $40(37.0)$ \\
\hline Others & $18(16.7)$ \\
\hline Extracapsular extension & $36(37.5)$ \\
\hline \multicolumn{2}{|l|}{ Tumor size staging } \\
\hline T0 & $1(0.9)$ \\
\hline T1a & $10(9.3)$ \\
\hline $\mathrm{T} 1 \mathrm{~b}$ & $13(12.0)$ \\
\hline $\mathrm{T} 2 \mathrm{a}$ & $60(55.7)$ \\
\hline $\mathrm{T} 2 \mathrm{~b}$ & $18(16.7)$ \\
\hline $\mathrm{T} 3$ & $6(5.6)$ \\
\hline \multicolumn{2}{|l|}{ Relapse site } \\
\hline $\mathrm{N}$ & $23(23.7)$ \\
\hline Local & $17(17.5)$ \\
\hline Distant & $23(23.7)$ \\
\hline Local+distant & $34(35.1)$ \\
\hline N/A (missing) & 11 \\
\hline Highest mediastinal LN involvement & $55(55.6)$ \\
\hline Median follow up period (days) & 869.5 \\
\hline
\end{tabular}

Abbreviations: SD: Standard deviation; CT: Chemotherapy; RT: Radiotherapy; LN: Lymph node
Table 2: Cox regression modeling result for disease free survival

\begin{tabular}{|c|c|c|c|c|c|}
\hline Variables & $\begin{array}{l}\text { Parameter } \\
\text { estimated }\end{array}$ & $\begin{array}{c}\text { Standard } \\
\text { error }\end{array}$ & $\begin{array}{l}\text { Hazard } \\
\text { ratio }\end{array}$ & $p$ & $\begin{array}{c}95 \% \\
\text { confidence } \\
\text { interval }\end{array}$ \\
\hline T stage & 0.21 & 0.16 & 1.23 & 0.19 & $(0.90,1.68)$ \\
\hline $\begin{array}{l}\text { Angiolymphatic } \\
\text { invasion }\end{array}$ & -0.16 & 0.25 & 0.84 & 0.51 & $(0.52,1.38)$ \\
\hline Perineural invasion & 1.11 & 0.45 & 3.04 & 0.01 & $(1.27,7.28)$ \\
\hline $\begin{array}{l}\text { Metastatic LN } \\
\text { ratio }>0.4\end{array}$ & 0.34 & 0.27 & 1.41 & 0.21 & $(0.82,2.40)$ \\
\hline $\begin{array}{l}\text { LN excapsular } \\
\text { extension }\end{array}$ & -0.16 & 0.19 & 0.85 & 0.38 & $(0.59,1.22)$ \\
\hline Category of operation & -0.72 & 0.41 & 0.48 & 0.08 & $(0.21,1.09)$ \\
\hline Post operation Tx & -0.16 & 0.31 & 0.85 & 0.59 & $(0.46,1.56)$ \\
\hline
\end{tabular}

Abbreviation: LN: Lymph node

Table 3: Cox regression modeling result for overall survival

\begin{tabular}{lccccc}
\hline Variables & $\begin{array}{c}\text { Parameter } \\
\text { estimated }\end{array}$ & $\begin{array}{c}\text { Standard } \\
\text { error }\end{array}$ & $\begin{array}{c}\text { Hazard } \\
\text { ratio }\end{array}$ & $p$ & $\begin{array}{c}95 \% \\
\text { confidence } \\
\text { interval }\end{array}$ \\
\hline $\begin{array}{l}\text { T stage } \\
\begin{array}{l}\text { Angiolymphatic } \\
\text { invasion }\end{array}\end{array}$ & -0.19 & 0.19 & 1.05 & 0.30 & $(0.83,1.76)$ \\
$\begin{array}{l}\text { Perineural } \\
\text { invasion }\end{array}$ & 1.12 & 0.46 & 3.05 & 0.01 & $(1.25,7.46)$ \\
$\begin{array}{l}\text { MetastaticLN } \\
\text { ratio }>0.4\end{array}$ & 0.78 & 0.33 & 2.18 & 0.01 & $(1.13,4.18)$ \\
$\begin{array}{l}\text { LN excapsular } \\
\text { extension }\end{array}$ & -0.38 & 0.32 & 0.68 & 0.24 & $(0.37,1.29)$ \\
$\begin{array}{l}\text { Category of } \\
\text { operation }\end{array}$ & -1.41 & 0.47 & 0.24 & 0.002 & $(0.09,0.61)$ \\
$\begin{array}{l}\text { Post operation } \\
\text { Tx }\end{array}$ & -0.58 & 0.38 & 0.56 & 0.13 & $(0.27,1.19)$ \\
\hline Abbreviation: LN: Lymph node & & & & \\
\hline
\end{tabular}

resection and post-operative adjuvant may be considered as a reasonable treatment plan cisplatin-based chemotherapy for resectable N2 NSCLC.

Analysis of treatment modalities showed anatomic resection as the major determinant factor. Anatomic resection exhibited a reduced hazard ratio in disease-free survival, but without statistical significance (hazard ratio: $0.48,95 \%$ confidence limits $0.21-1.09 ; p=0.08)$. However, anatomic resection exhibited a reduced hazard ratio in overall survival (hazard ratio: $0.24,95 \%$ confidence limits $0.09-0.21 ; p=0.002$ ), which may be attributed to the protective effect of anatomic resection. This protective effect may be caused by the possibilities of occult metastases of N2 disease. This result implies that anatomic resection with mediastinal lymph node dissection can be used to remove as much tumor tissue as possible. Therefore, the lesser the remaining tumor tissue, the longer the patient would survive. In our study, only 14 patients underwent preoperative neoadjuvant therapy. Because of the limited number of cases, we could not account for the preoperative neoadjuvant's effect on disease-free and overall survival rates. In our study, the 


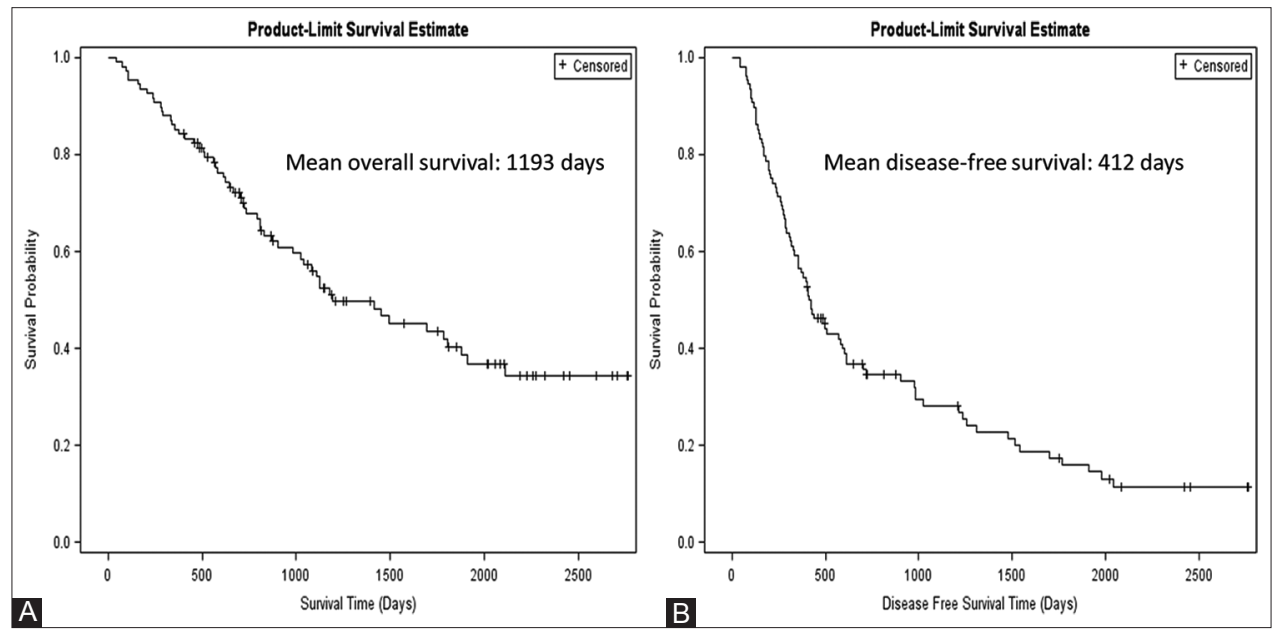

Figure 2: (A) Overall survival curve of all patients; (B) disease-free survival curve of all patients.

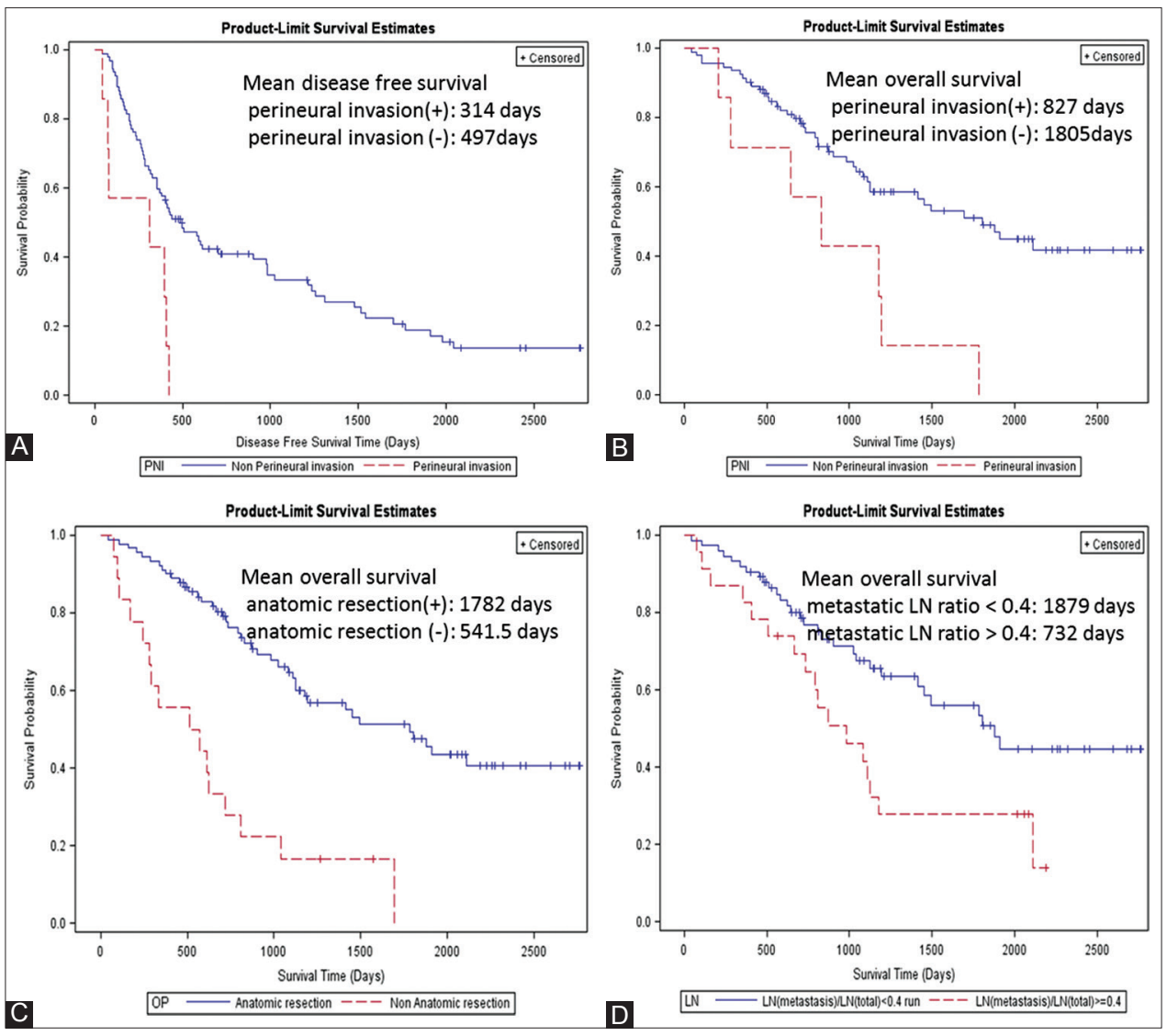

Figure 3: (A) Disease-free survival curve of patients with and without perineural invasion (hazard ratio: 3.04, 95\% confidence limits 1.27-7.28; $p=0.01$ ); (B) overall survival curve of patients with and without perineural invasion (hazard ratio: 3.05, 95\% confidence limits 1.25-7.46; $p=0.01$ ); (C) overall survival curve of patients who underwent anatomic resection and those who underwent non-anatomic resection (hazard ratio: $0.24,95 \%$ confidence limits $0.09-0.61 ; p=0.002)$; (D) overall survival curve of patients with metastatic lymph node ratio greater and less than 0.4 (hazard ratio: $2.18,95 \%$ confidence limits $1.13-4.18 ; p=0.01$ ).

postoperative therapy also did not show any significant effect on the disease-free and overall survival rates. But postoperative therapies such as radiotherapy and chemotherapy may have protective effects on the overall survival rate (hazard ratio: $0.38 ; 95 \%$ confidence limits $0.27-1.19 ; p=0.13$ ). Miller et al. had demonstrated similar findings, where the 5-year survival rate was $23.7 \% .^{[18]}$ Further investigations are still required to identify the relationship between treatment modality and survival rate. However, anatomic resection may play a crucial role on overall survival in patients with resectable $\mathrm{N} 2$ disease. 
We further analyzed the characteristic features of tumor cells among patients who underwent anatomic resection, in order to identify its effect on disease-free and overall survival rates. Previous studies had reported that several pathological factors were related to survival rate; these factors include visceral pleural invasion, ${ }^{[19-22]}$ vascular invasion, ${ }^{[23]}$ perineural invasion, ${ }^{[24-26]}$ histologic grade, ${ }^{[27]}$ and nuclear atypia. ${ }^{[28]}$ Our multivariate analysis indicated that only perineural invasion had a significant effect on disease-free and overall survival rates among N2 NSCLC patients. Perineural invasion was defined as cancer cell spreading to the space surrounding a nerve and was confirmed by the pathologist. In literature reports, the reported incidence of perineural invasion was $3-29 \% .^{[24-26]}$ In our study, the incidence was $7.1 \%$ and this result is similar to that reported in the study of Poncelet et al. ${ }^{[25]}$ In addition, the majority $(6 / 7,85.7 \%)$ of patients with perineural invasion had tumor cells with moderate to poor differentiation. Because of the limited number of cases, further investigations are still required to identify its clinical significance and to understand the actual mechanism of perineural invasion that can lead to poor disease-free and overall survival rates.

The low survival of $\mathrm{N} 2$ disease can be attributed to mediastinal lymph node involvement. Previous reports mentioned that the survival of $\mathrm{N} 2$ disease is characterized by several subgroups with variable survival rates. Okada et al. showed patients with following mediastinal metastasis would have acceptable survival after radical resection, including those with upper nodes from upper lobe tumor, lower nodes from lower lobe tumor, or aortic nodes from left upper lobe tumor. ${ }^{[12]}$ In addition, patients with skip metastases, ${ }^{[5,29]}$ without extracapsular spread,${ }^{[6]}$ and with single station ${ }^{[1,16]}$ involvement exhibited better survival rates. However, even with demonstration of these studies, there is still no consensus on the factors affecting the survival rates. The reason for the non-consensus is the complex nature of the lymphatic pathway to the mediastinum. Riquet et al. had reported that direct lymph channels into the mediastinum are more frequently observed in the upper lobes. ${ }^{[30]}$

Imai et al. utilized indocyanine injection for pulmonary lymphatic drainage survey in their study and showed that $21.4 \%$ of N2 NSCLC patients had direct lymphatic flow to the mediastinum (3/14). ${ }^{[31]}$ In our study, mediastinal lymph node involvement factors were not related to disease-free survival. This may be related to the possible systemic tumor spread of N2 disease. However, the severity of mediastinal lymph node, i.e. metastatic lymph node ratio, still had a significant impact on the overall survival rate. Wang et al. showed that metastatic lymph node ratio greater than 0.18 is a poor prognostic factor among stage II-IIIa patients. ${ }^{[32]}$ In our study, we found that $\mathrm{N} 2$ patients with metastatic lymph node ratio greater than 0.4 had poor overall survival. Generally, the more extensive is the tumor spread in the mediastinum lymph node, the more unoptimistic the prognosis would be. However, in our study, only stage IIIa with N2 disease patients were included. This may be the reason why our cut-off value of metastatic lymph node ratio was greater than that of the Wang's study.

There are some limitations in this study. (1) Due to its retrospective nature, the treatments were determined by the clinical decisions of the physicians caring for the patients under the principle of intent to treatment and following the guidelines set by the hospital. The patients were not randomized to each treatment group and selection bias might exist, which could influence the disease-free and overall survival rates. (2) Although all the patients in the present study were evaluated for their lesions by chest radiograph, CT, MRI, bone scintigraphy, or PET according to predetermined management protocols set by the hospital, the intervals between evaluations were not as accurate as those in a prospective trial, which may also affect the precision of disease-free and overall survival rates. (3) We included 18 patients who underwent wedge resection and mediastinal lymph node sampling because of poor pulmonary reserve. The poor general condition of these patients and the selected surgical procedure may lead to poor survival thereafter. However, patients who received anatomic resection in our study still showed non-inferior outcome to Koshy's result ${ }^{[17]}$ (5-year overall survival: $48.2 \%$ vs. $33.5 \%$ ). (4) The study population was small and epidermal growth factor receptor (EGFR) mutation data was lacking for further subgroup survival analysis. (5) There were only seven patients who were identified with perineural invasion, but the effects of prognosis need further investigation due to the small population. Even through limitations remain, our study still provided clinical information for management of pathologic N2 NSCLC patients.

\section{Conclusions}

Metastatic lymph node ratiogreater than 0.4 and non-anatomic resection were poor prognostic factors for overall survival. Survival of N2 disease is influenced not only by tumor cell characteristics, but also by the mediastinal involvement status. Perineural invasion was found to be a poor prognostic factor for disease-free survival of N2 NSCLC, but needs further investigation due to the small study sample. Finally, anatomic resection for selected N2 patients may play a crucial role in improving overall survival.

\section{REFERENCES}

1. Misthos P, Sepsas E, Kokotsakis J, Skottis I, Lioulias A. The significance of one-station N2 disease in the prognosis of patients with nonsmall-cell lung cancer. Ann Thorac Surg 2008;86:1626-30.

2. Detterbeck FC, Boffa DJ, Tanoue LT. The new lung cancer staging system. Chest 2009;136:260-71.

3. Vansteenkiste JF, De Leyn PR, Deneffe GJ, Stalpaert G, 
Nackaerts KL, Lerut TE, et al. Survival and prognostic factors in resected N2 non-small cell lung cancer: A study of 140 cases. Leuven Lung Cancer Group. Ann Thorac Surg 1997;63:1441-50.

4. Nakanishi R, Osaki T, Nakanishi K, Yoshino I, Yoshimatsu T, Watanabe $\mathrm{H}$, et al. Treatment strategy for patients with surgically discovered N2 stage IIIA non-small cell lung cancer. Ann Thorac Surg 1997;64:342- 8 .

5. Misthos P, Sepsas E, Athanassiadi K, Kakaris S, Skottis I. Skip metastases: Analysis of their clinical significance and prognosis in the IIIA/N2 NSCLC group. Eur J Cardiothorac Surg 2004;25:502-8.

6. Detterbeck F. What to do with "surprise" N2? Intraoperative management of patients with non-small cell lung cancer. J Thorac Oncol 2008;3:289-302.

7. van Meerbeeck JP, Surmont VF. Stage IIIA-N2 NSCLC: A review of its treatment approaches and future developments. Lung Cancer 2009;65:257-67.

8. Ratto GB, Costa R, Maineri P, Alloisio A, Bruzzi P, Dozin B. Is there a subset of patients with preoperatively diagnosed N2 non-small cell lung cancer who might benefit from surgical resection. J Thorac Cardiovasc Surg 2009;138:849-58.

9. Ramnath N, Dilling TJ, Harris LJ, Kim AW, Michaud GC, Balekian AA, et al. Treatment of stage III non-small cell lung cancer: Diagnosis and management of lung cancer, $3^{\text {rd }}$ ed: American College of Chest Physicians evidence-based clinical practice guidelines. Chest 2013;143 Suppl 5:e314-40S.

10. Arriagada R, Bergman B, Dunant A, Le Chevalier T, Pignon JP, Vansteenkiste $\mathrm{J}$, et al.; International Adjuvant Lung Cancer Trial Collaborative Group. Cisplatin-based adjuvant chemotherapy in patients with completely resected non-small-cell lung cancer. N Engl J Med 2004;350:351-60.

11. Kirmani BH, Rintoul RC, Win T, Magee C, Magee L, Choong C, et al. Stage migration: Results of lymph node dissection in the era of modern imaging and invasive staging for lung cancer. Eur $\mathbf{J}$ Cardiothorac Surg 2013;43:104-9.

12. Okada M, Tsubota N, Yoshimura M, Miyamoto Y, Matsuoka H. Prognosis of completely resected pN2 non-small cell lung carcinomas: Whatis the significant node that affects survival? J Thorac Cardiovasc Surg 1999;188:270-5.

13. Watanabe Y, Shimizu J, Oda M, Hayashi Y, Watanabe S, Tatsuzawa Y, et al. Aggressive surgical intervention in N2 non- small cell cancer of the lung. Ann Thorac Surg 1991;51:253-61.

14. Martini N, Flehinger BJ. The role of surgery in N2 lung cancer. Surg Clin North Am 1987;67:1037-49.

15. Naruke T, Goya T, Tsuchiya, Suemasu K. The importance of surgery to non-small cell carcinoma of lung with mediastinallymph node metastasis. Ann Thorac Surg 1988;46:603-10.

16. Goldstraw P, Mannam GC, Kaplan DK, Michail P. Surgical management of non-small cell lung cancer with ipsilateral mediastinal node metastasis (N2 disease). J Thorac Cardiovasc Surg 1994;107:19-27.

17. Koshy M, Fedewa SA, Malik R, Ferguson MK, Vigneswaran WT, Feldman L, et al. Improved survival associated with neoadjuvant chemoradiation in patients with clinical stage IIIA(N2) non-small-cell lung cancer. J Thorac Oncol 2013;8:915-22.

18. Miller DL, McManus KG, Allen MS, Ilstrup DM, Deschamps C,
Trastek VF, et al. Results of surgical resection in patients with N2 non-small cell lung cancer. Ann Thorac Surg 1994;57:1095-100.

19. Shimizu K, Yoshida J, Nagai K, Nishimura M, Ishii G, Morishita Y, et al. Visceral pleural invasion is an invasive and aggressive indicator of nons mall cell. J Thorac Cardiovasc Surg 2005;130:160-5.

20. Ou SI, Zell AJ, Ziagos A, Anton-Culver H. Prognostic significance of the non size based AJCC T2 descriptors: Visceral pleura invasion, hilar atelectasis, or obstructive pneumonia in stage IB non-small cell lung cancer is dependent on size. Chest 2008;133:662-9.

21. Osaki T, Nagashima A, Yoshimatsu T, Yamada S, Yasumoto K. Visceral pleural involvement in nonsmall cell lung cancer: Prognostic significance. Ann Thorac Surg 2004;77:1769-73.

22. Inoue M, Minami M, Shiono H. Sawabata N, Ideguchi K, Okumura M. Clinicopathologic study of resected, peripheral, small-sized, non-small cell lung cancer tumors of $2 \mathrm{~cm}$ or less in diameter: Pleural invasion and increase of serum carcinoembroyonic antigen level as predictors of nodal involvement. J Thorac Cardiovasc Surg 2006;131:988-93.

23. Tsuchiya T, Hashizume S, Akamine S, Muraoka M, Honda S, Tsuji K, et al. Upstaging by vessel invasion improves the pathology staging system of non-small cell lung cancer. Chest 2007;132:170-7.

24. Sayar A, Turna A, Solak O, Kiliçgün A, Urer N, Gürses A. Nonanatomic prognostic factors in resected non-small cell lung carcinoma: The importance of perineural invasion as a new prognostic marker. Ann Thorac Surg 2004;77:421-5.

25. Poncelet AJ, Cornet J, Coulon C, Collard P, Noirhomme P, Weynand $\mathrm{B}$, et al.; groupe d'oncologie thoracique des Cliniques Saint-Luc. Intra-tumoral vascular or perineural invasion as prognostic factors for long-term survival in early stage non-small cell lung carcinoma. Eur J Cardiothorac Surg 2008;33:799-804.

26. Yilmaz A, Duyar SS, Cakir E, Aydin E, Demirag F, Karakaya J, et al. Clinical impact of visceral pleural, lymphovascular and perineural invasion in completely resected non-small cell lung cancer. Eur J Cardiothorac Surg 2011;40:664-70.

27. Ou SH, Zell JA, Ziagos A, Anton-Culver H. Prognostic factors for survival of stage I non small cell lung cancer patients: A population-based analysis of 19,702 stage I patients in the California Cancer Registry from 1989 to 2003. Cancer 2007;110:1532-41.

28. Takise A, Kodama T, Shimosato Y, Watanabe S, Suemasu K. Histopathologicprognostic factors in adenocarcinomas of the peripheral lung less than $2 \mathrm{~cm}$ in diameter. Cancer 1988;61:2083-8.

29. Prenzel KL, Mönig SP, Sinning JM, Baldus SE, Gutschow CA, Grass G, et al. Role of skip metastasis to mediastinal lymph nodes in non-small cell lung cancer. J Surg Oncol 2003;82:256-60.

30. Riquet M, Manac'h D, Saab M, Le Pimpec-Barthes F, Dujon A, Debesse B. Factors determining survival in resected N2 lung cancer. Eur J Cardiothorac Surg 1995;9:300-4.

31. Imai $\mathrm{K}$, Minamiya $\mathrm{Y}$, Saito $\mathrm{H}$, Nakagawa $\mathrm{T}$, Ito $\mathrm{M}$, Ono $\mathrm{T}$, et al. Detection of pleural lymph flow using indocyanine green fluorescence imaging in non-small cell lung cancer surgery: A preliminary study. Surg Today 2013;43:249-54.

32. Wang CL, Li Y, Yue DS, Zhang LM, Zhang ZF, Sun BS. Value of the metastatic lymph node ratio for predicting the prognosis of non-small-cell lung cancer patients. World J Surg 2012;36:455-62. 